\title{
Amide-modified poly(butylene terepthalate): thermal stability
}

\author{
A. C. M. van Bennekom*, P. A. A. T. Willemsen and R. J. Gaymanst \\ University of Twente, PO Box 217, 7500 AE Enschede, The Netherlands \\ (Received 21 February 1996)
}

\begin{abstract}
The thermal stability of a poly(ester amide) copolymer (PBTA) based on poly(butylene terephthalate) (PBT) and nylon-4,T with the diamide of butanediamine and dimethyl terephthalate $\left(N, N^{\prime}\right.$-bis $(p$-carbomethoxybenzoyl)butanediamine) and homopolymer PBT was studied. The development of inherent viscosity and endgroup concentration was determined during prolonged condensation reactions at $255-$ $275^{\circ} \mathrm{C}$. Analysis of the kinetics lead to degradation rate constants for PBT and PBTA with $20 \mathrm{~mol} \%$ amide (PBTA20). The degradation rate of PBTA20 was comparable to that of PBT, thus $\beta$-elimination of the ester groups is the main degradation mechanism in PBTA. At high temperatures ester-amide interchange reactions also take place in PBTA. The change in the melting temperature of PBTA has been related to the decreasing uniformity of the amide segment length. The decomposition was further studied by thermogravimetry and mass spectrometry. Copyright (C) 1996 Elsevier Science Ltd.
\end{abstract}

(Keywords: poly(butylene terephthalate); butanediamine; poly(ester amide)s)

\section{INTRODUCTION}

The thermal stability of poly(ester amide)s plays a role during polymerization, during melt processing and in applications at high temperature. Degradation is generally associated with chain cleavage, but it can also affect the chemical structure, e.g. by interchange reactions ${ }^{1}$. When the chemical stability of ester and amide bonds is compared, both react readily with polar substances (water, alcohols, amines and the like). The amide bond, however, is thermally more stable than the ester bond due to its partial double bond character ${ }^{2,3}$.
There is an accepted mechanism for the thermal degradation of poly(butylene terephthalate) (PBT) ${ }^{4}$. Only recently, a mechanism for the degradation of poly(butylene terephthalamide) (nylon-4,T) has been proposed ${ }^{5}$. The thermal degradation of their copolymers may show both types of mechanism. Poly(ester amide)s (PBTA) based on PBT and diamide units of butanediamine and dimethyl terephthalate $\left(N, N^{\prime}\right.$-bis $(p$-carbomethoxybenzoyl)butanediamine) have been synthesized ${ }^{6}$. We studied the thermal stability of PBTA with $20 \%$ amide units. This means that $x$ in the following formula has an average value of 4 :

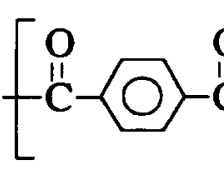

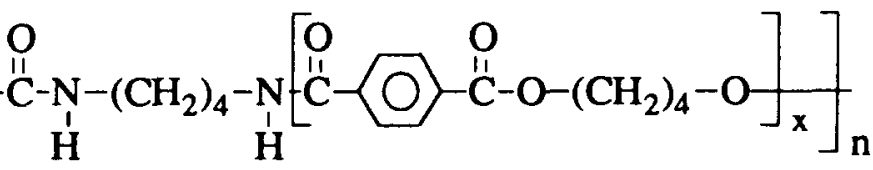

PBTA

This originates from a mesomeric effect:

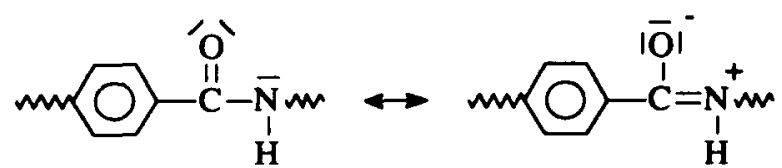

\footnotetext{
* Present address: GE Plastics, PO Box 117, 4600 AC Bergen op Zoom, The Netherlands

† To whom correspondence should be addressed
}

\section{Thermal degradation reactions}

The main thermal degradation reactions for PBT are cyclization and $\beta$-elimination. Pilati et al. ${ }^{\top}$ proposed intramolecular mechanisms for these degradation reactions: cyclization by 'back-biting' and $\beta$-elimination via a cyclic intermediate. Cyclization of butanediol [reaction (2)] and cyclization of hydroxybutyl endgroups [reaction (3)] both occur above $200^{\circ} \mathrm{C}$ and tetrahydrofuran (THF) is formed. Relatively large cyclic dimers and trimers can also be formed; PBT contains about $1-2 \mathrm{wt} \%$ of cyclic oligomers ${ }^{8}$.

Pilati et al..$^{7}$ reported that degradation via $\beta$-elimination becomes noticeable at higher temperatures and occurs simultaneously with polymerization. Carboxylic 


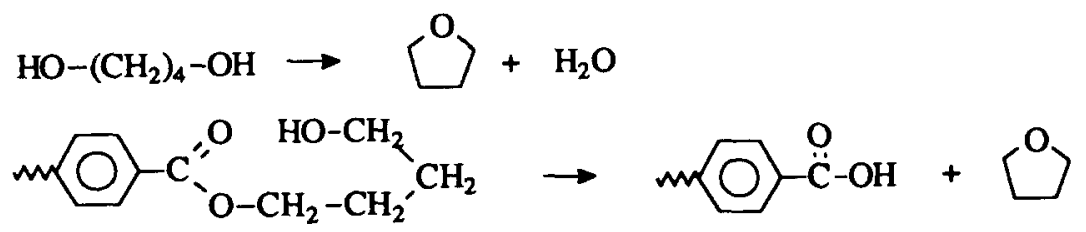

acids and unsaturated terephthalate endgroups could be detected after a degradation test of PBT at $280^{\circ} \mathrm{C}^{7,9,10}$. The mechanism was assumed to be intramolecular and involves the formation of a cyclic transition state [reactions (4a) and (4b)]. Deveaux et al. ${ }^{11}$ ascribed the relatively high degradation rate of $P B T$ (in the temperature range of processing) to the flexibility of the butylene segment in PBT.

Passalacqua et al. ${ }^{9}$ observed that the second step, splitting of butadiene from the unsaturated endgroup [reaction (4b)], occurred much faster than the first step (thus $k_{2} \gg k_{1}$ ). The formation of a cyclic intermediate would be favoured by conjunction of electrons in the unsaturated 3-butenyl ester endgroup: polyamides, thermal degradation can occur analogous to mechanisms discussed for polyesters. Gaymans and co-workers ${ }^{14,15}$ found for nylon- $4, T$ that the cyclization of butanediamine into pyrrolidine leads to monomer loss [reaction (5)] and terminating endgroups [reaction (6)]. Ballistreri et al. ${ }^{16}$ reported that the $\beta$-elimination of amide bonds results in primary amide endgroups and unsaturated terephthalamide endgroups [reaction (7a)]. The secondary reaction ( $7 b$ ), dehydration of the primary amide into nitrile and water, has been demonstrated for aliphatic-aromatic and aromatic polyamides by mass spectrometry ${ }^{17-19}$.

In the case of alternating poly(ester amide)s ' $n \mathrm{NT} m$ ' with short-chain glycols ( $m$ is $2-5$ ) or diamines ( $n$ is 4 ),

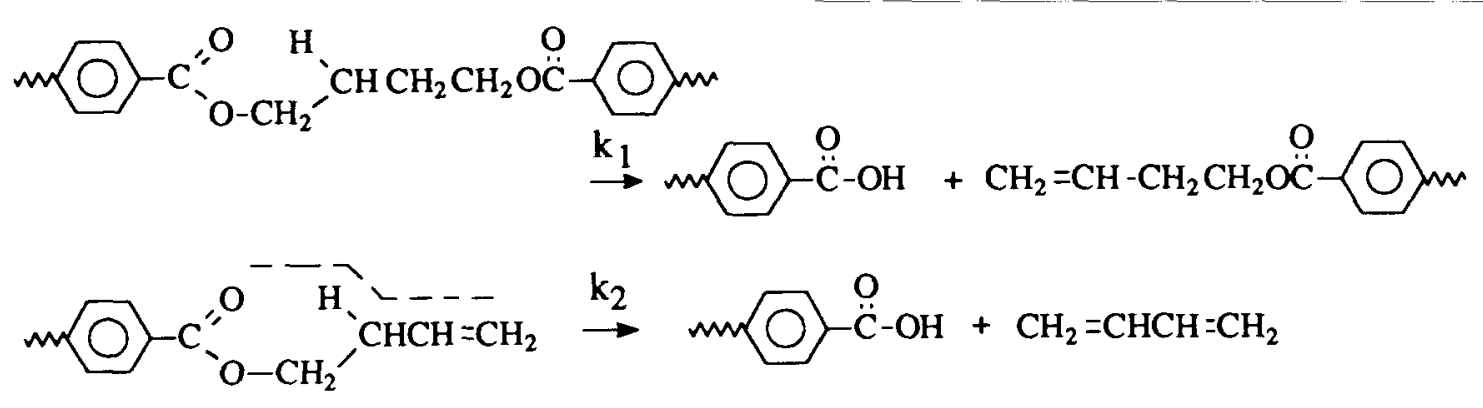

Hudson and Barker ${ }^{12}$ reported that the cyclization in PBT is accelerated by the presence of carboxylic acid endgroups. Passalacqua et $a l^{9}{ }^{9}$ reported that the $\beta$-elimination of ester groups in PBT is not only polymers of very low molecular weight could be obtained $^{20}$. Manzini et $a .^{20}$ explained this by the occurrence of side-reactions during the synthesis of these poly(ester amide)s.

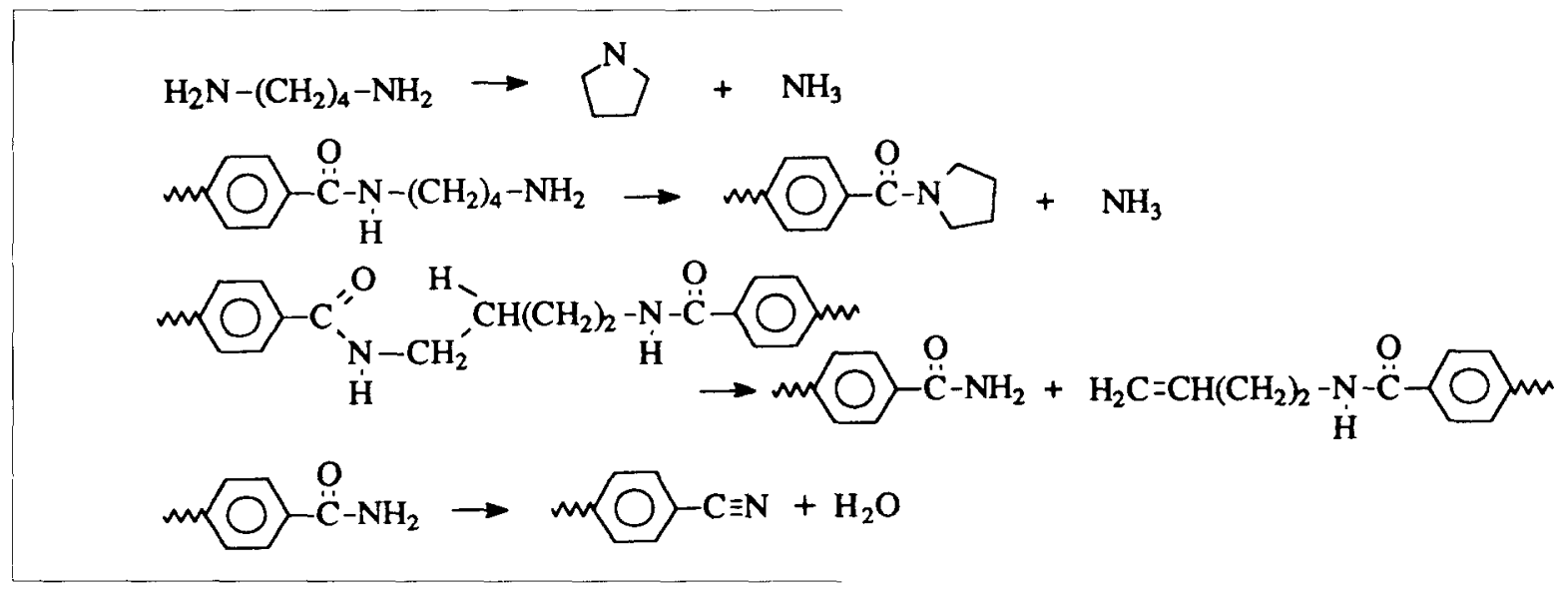

catalysed by the generated $\mathrm{COOH}$ endgroups. Furthermore, Pilati et al. ${ }^{7}$ found that, contrary to the case of poly(ethylene terephthalate) (PET) ${ }^{13}$, the degradation of PBT was not affected by the catalyst $\mathrm{Ti}(\mathrm{OBu})_{4}$.

Despite the high stability of aromatic-aliphatic
Pilati et $a l^{21}$ found for alternating poly(ester amide)s that the predominant thermal degradation occurred by random cleavage ( $\beta$-elimination) of ester bonds. The rate of ester degradation appeared to increase in the presence of amide bonds on the para-position of esters of terephthalic acid. 
Table 1 Possible interchange and exchange reactions between esters and amides (after Kotliar ${ }^{22}$ )

I

cyclization of butanediamine endgroups

$$
\stackrel{\mathrm{CONH}-\left(\mathrm{CH}_{2}\right)_{4}-\mathrm{NH}_{2}}{\longrightarrow}-\mathrm{CO}-\mathrm{N} \Omega+\mathrm{NH}_{3}
$$

II aminolysis of amides

$$
\underset{+\mathrm{H}_{2} \mathrm{~N}-}{-\mathrm{NH}-\mathrm{CO}-}=\frac{\mathrm{NH}_{2}+\underset{1}{\mathrm{CO}-}}{\mathrm{NH}-}
$$

III

acidolysis of amides

$$
\begin{aligned}
& -\mathrm{NH}-\mathrm{CO}- \\
& \stackrel{+}{\mathrm{COOH}}=\begin{array}{l}
-\mathrm{NH}+\mathrm{HOOC}- \\
-\mathrm{CO}
\end{array}
\end{aligned}
$$

IV transamidation

$$
\begin{aligned}
& -\mathrm{NH}-\mathrm{CO}- \\
& { }_{-} \mathrm{CO}-\mathrm{NH}-
\end{aligned}=\begin{aligned}
& -\mathrm{NH} \\
& -\mathrm{CO}- \\
& -\mathrm{CO}+
\end{aligned}
$$

$\mathrm{V}$ alcoholysis of amides

$$
\begin{aligned}
& -\mathrm{NH}-\mathrm{CO}- \\
& +\mathrm{HO}-
\end{aligned}=\begin{array}{r}
-\mathrm{NH}_{2}+\underset{\mathrm{O}}{\mathrm{CO}} \\
\mathrm{O}-
\end{array}
$$

VI

ester-amide interchange cyclization of butanediol endgroups

$$
-\mathrm{COO}-\left(\mathrm{CH}_{2}\right)_{4}-\mathrm{OH}
$$

$$
\rightarrow-\mathrm{COOH}+\mathrm{O}^{-}
$$

alcoholysis of esters

$$
\begin{gathered}
-\mathrm{O}-\mathrm{CO}- \\
+\mathrm{HO}-
\end{gathered}=\begin{gathered}
-\mathrm{OH}+\mathrm{CO}- \\
\mathrm{O}-
\end{gathered}
$$

acidolyis of esters

$$
\begin{aligned}
& -\mathrm{O}-\mathrm{CO}- \\
& { }_{-}^{+} \mathrm{COOH}
\end{aligned}=\begin{aligned}
& -\mathrm{O}+\mathrm{HOOC}- \\
& -\mathrm{CO}
\end{aligned}
$$

transesterification

$$
\begin{aligned}
& -\mathrm{O}-\mathrm{CO}- \\
& \stackrel{+}{+} \mathrm{CO}^{-}
\end{aligned}=\begin{aligned}
& -\mathrm{O} \\
& -\mathrm{CO}
\end{aligned}+\stackrel{\mathrm{CO}-}{\mathrm{O}-}
$$

aminolysis of esters

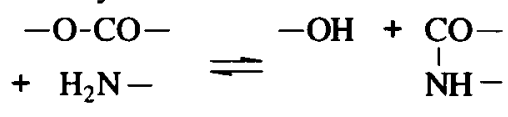

$$
\underset{-\mathrm{CO}-\mathrm{NH}-}{+\mathrm{O}-\mathrm{CO}-}=\underset{-\mathrm{CO}}{-\mathrm{O}}+\underset{\mathrm{NH}-}{\mathrm{CO}-}
$$

\section{Esterolysis and amidolysis}

Kotliar $^{22}$ distinguished four possible types of interchange reactions in polyesters and polyamides (Table 1 ). Type I involves 'back-biting' reactions of endgroups which results in cyclic products (tetrahydrofuran, pyrrolidine endgroups, dimer split-off). Type II is an interchange of the polar endgroup with a similar bond, e.g. alcoholysis of ester bonds. This is in fact a normal interchange reaction and inherent to condensation equilibria. When carboxylic acid endgroups are present (type III), acidolysis of esters or amides can occur. Type IV represents ester-ester and amide-amide interchange, or transesterification and transamidation respectively.

The rate of polymer degradation by acidolysis, alcoholysis or aminolysis depends on the concentration of endgroups, Korshak and Frunze ${ }^{23}$ reported that these reactions are first order in concentration of $\mathrm{COOH}, \mathrm{OH}$ or $\mathrm{NH}_{2}$ endgroups, respectively. As a consequence, the degradation rate is inversely related to the numberaverage molecular weight of the polymer. The relative rates of interchange reactions, as well as the degree of acid catalysis or the role of water, have scarcely been described in the literature.

\section{Ester-amide interchange}

Flory ${ }^{24}$ assumed that the driving force for interchange reactions in copolymers is generally towards maximal entropy. This would be achieved with a most probable, random, distribution of monomer units in a polymer. Kotliar et al. ${ }^{22}$ mentioned that the use of ester-amide interchange for the preparation of poly(ester amide)s was often reported in patents and inaccessible Russian literature. Korshak ${ }^{25}$ observed the formation of copolymers starting from a melt mixture of aliphatic polyester and nolyamide. Ester-amide interchange was assumed to take place through interaction of amide and ester groups of neighbouring chains (type VI in Table 1).

Korshak et $a l^{25}$ also indicated the possibility of exchange through active endgroups (aminolysis of esters or alcoholysis of amides, type V). Without catalyst no reaction took place but in the presence of about $2 \mathrm{wt} \%$ of $\mathrm{PbO}, \mathrm{PbAc}_{2}$ or $\mathrm{LiOH}$, the interchange at $260^{\circ} \mathrm{C}$ proceeded within several hours. A mechanism for the catalysis was not given.

Della Fortuna $e t a l^{26}$ studied the effect of ester-amide interchange on order in the alternating poly(ester amide) 6NT6. By keeping the polymer for a long time above its melting point, an extensive molecular rearrangement into an almost random distribution of ester and amide linkages took place. Besides the main peak in differential scanning calorimetry curves, the products also showed higher and lower melting peaks. A possible effect of the titanate, used for the synthesis of 6NT6, was not mentioned. We have calculated that, based on the addition of $0.02 \mathrm{~mol} \% \mathrm{Ti}\left(\mathrm{i}-\mathrm{OC}_{3} \mathrm{H}_{7}\right)_{4}$, the titanium content was only $19 \mathrm{ppm}$.

Dimov and Georgiev ${ }^{27}$ reported the occurrence of noncatalytic ester-amide interchange in melt mixtures of PET and nylon-6. The melting temperature of PET as well as nylon-6 decreased only after several hours at $270^{\circ} \mathrm{C}$. The content of amino endgroups decreased almost simultaneously. The randomization was mainly ascribed to a slow process of aminolysis of the ester bonds.

Catalytic ester-amide interchange reactions in melt blends of PET/polyamide have also been reported. In the presence of $\mathrm{ZnAc}_{2}$ and $\mathrm{SbO}_{3}$, block copolymers were formed after $5 \mathrm{~h}^{28}$. Pillon and Utracki ${ }^{29}$ used $p$-toluene sulfonic acid $(\mathrm{TsOH})$ as interchange catalyst in PET/ nylon-6,6 melt mixtures. However, Brown ${ }^{30}$ suggested that $\mathrm{TsOH}$ catalysed the interchange of an amino 
endgroup with an ester group of PET instead of direct ester-amide interchange.

To gain insight into the thermal stability of PBTA, the thermal degradation and thermal decomposition of the material are studied and compared with those of PBT.

\section{EXPERIMENTAL}

\section{Materials}

Dimethyl terephthalate (DMT), 1,4-butanediamine (BDA) and 1,4-butanediol (BDO) were obtained from Merck. The diamide from BDA and an excess of DMT $\left(N, N^{\prime}\right.$-bis ( $p$-carbo-methoxybenzoyl)butanediamine, T4T.dimethyl) was synthesized using $\mathrm{LiOCH}_{3}$ as catalyst $^{6}$. The PBT and PBTA were synthesized with $\mathrm{Ti}\left(\mathrm{i}-\mathrm{OC}_{3} \mathrm{H}_{7}\right)_{4}$ as catalyst. $\mathrm{Ti}\left(\mathrm{i}-\mathrm{OC}_{3} \mathrm{H}_{7}\right)_{4}$ was distilled and diluted in anhydrous $m$-xylene $(0.175 \mathrm{M})$.

\section{Degradation test at $270^{\circ} \mathrm{C}$}

PBT and PBTA20 were first synthesized in a $250 \mathrm{ml}$ glass flask under standard conditions $\left(1 \mathrm{~h}\right.$ at $255^{\circ} \mathrm{C}$ and reduced pressure $)^{6}$. Then, the temperature of the oil bath was raised to $270^{\circ} \mathrm{C}$ and either a preheated $\mathrm{N}_{2}$ flow or vacuum was applied. Each hour about $1 \mathrm{~g}$ of sample was taken and quenched in liquid nitrogen.

\section{Thermogravimetric analysis (t.g.a.)}

Thermogravimetric studies were performed on a Perkin-Elmer TGA7 with a heating rate of $10^{\circ} \mathrm{C} \mathrm{min}-1$ in $\mathrm{N}_{2}$ or air. The average decomposition temperature (ADT) was defined by the maximum of a differential curve; the L(ower)DT and U(pper)DT by the start and end points.

\section{Mass spectrometry (EI-DP m.s.)}

Mass spectrometry with direct pyrolysis (DP) and electron impact (EI) ionization $(18 \mathrm{keV})$ was performed on a Finnigan MAT 90, double focusing and at a resolution of $1: 50.000$. About $1 \mathrm{mg}$ of dried polymer powder was placed in a direct insertion probe. The scan rate was $3 \mathrm{~s} / \mathrm{d}$. Mass spectra (intensity versus $\mathrm{m} / \mathrm{e}$ ) were determined at 200 and $300^{\circ} \mathrm{C}$. The total ion current (TIC) was detected during a gradual increase of temperature, from 30 to $360^{\circ} \mathrm{C}$ at a rate of $10^{\circ} \mathrm{C} \mathrm{min}^{-1}$. The maximum in the TIC curve corresponded with the highest decomposition rate during pyrolysis ${ }^{31}$. The TIC was also detected during stepwise (200 and $300^{\circ} \mathrm{C}$ ) increase of the temperature to distinguish lowmolecular-weight products in the polymer from degradation products. Analogously, the current of a single molecular ion (SIC) was followed. The ratio of a molecular ion to its fragments was defined as relative intensity current (RIC).

\section{Viscometry}

The inherent viscosity $\eta_{\text {inh }}$ was determined of a $0.5 \mathrm{~g} \mathrm{dl}^{-1}$ solution in phenol/1,1,2,2-tetrachloroethane $(36 / 64 \mathrm{wt} \%)$ using a capillary Ubbelohde $1 \mathrm{~b}$, at $25.0 \pm 0.05^{\circ} \mathrm{C}$.

\section{Differential scanning calorimetry (d.s.c.)}

A Perkin-Elmer DSC7 equipped with a PE-7700 computer and TAS-7 software was used to analyse the melting and crytallization transitions at a heating and

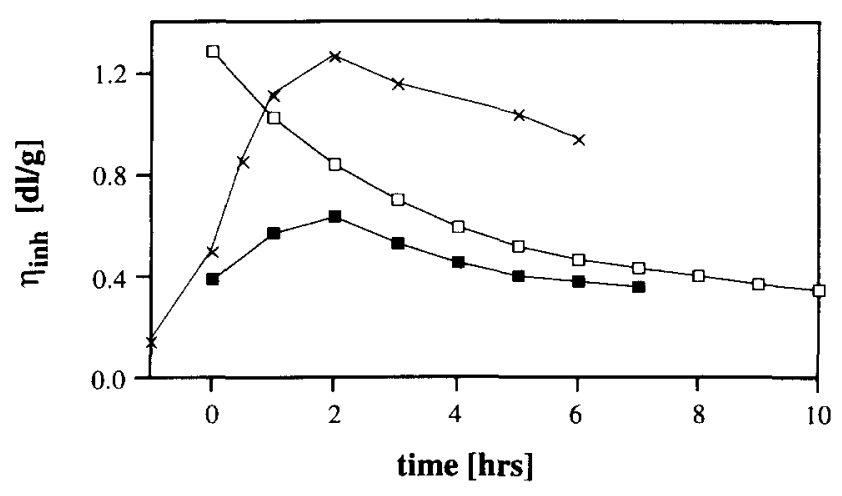

Figure 1 Inherent viscosity versus time for PBT: $\times, 255^{\circ} \mathrm{C} /$ vacuum; $\square, 270^{\circ} \mathrm{C} / \mathrm{N}_{2} ; \mathbf{D}, 270^{\circ} \mathrm{C} /$ vacuum

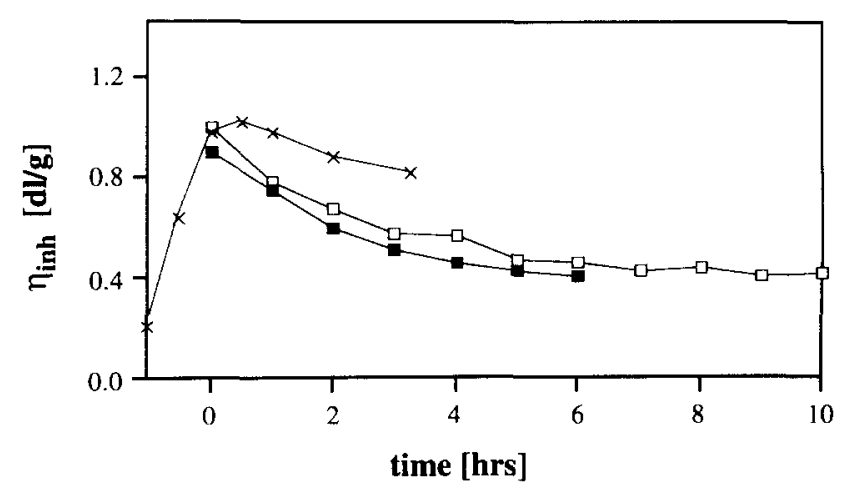

Figure 2 Inherent viscosity versus time for PBTA20: $\times, 255^{\circ} \mathrm{C}$ vacuum; $\square, 270^{\circ} \mathrm{C} / \mathrm{N}_{2} ; \mathbf{\square}, 270^{\circ} \mathrm{C} /$ vacuum

cooling rate of $20^{\circ} \mathrm{Cmin}^{-1}$. The peak maximum was taken as the transition temperature $T_{\mathrm{m}}$ or $T_{\mathrm{c}}$ and the area under the curve as $\Delta H$. For T4T.dimethyl the first heating scan $\left(T_{\mathrm{m}, 1}, \Delta H_{\mathrm{m}, 1}\right)$ was used, for PBTA the second heating scan $\left(T_{\mathrm{m}, 2}, \Delta H_{\mathrm{m}, 2}\right)$. Tin was used as calibration standard.

\section{Nuclear magnetic resonance (n.m.r.) spectroscopy}

${ }^{1} \mathrm{H}$ n.m.r. and proton decoupled ${ }^{13} \mathrm{C}$ n.m.r. spectra were recorded on a Bruker AC 250 spectrometer at 250.1 and $62.9 \mathrm{MHz}$, respectively. Deuterated trifluoroacetic acid (TFA-d) was used as solvent without internal standard. ${ }^{13} \mathrm{C}$ n.m.r. scans $(3200)$ were taken with an acquisition time of $2.097 \mathrm{~s}$ and a $45^{\circ}$ pulse.

\section{Endgroup analysis}

The endgroup content was determined with a Titroprocessor Metrohm 636 equipped with a Dosimat E635. The titrants used were trifluoromethane sulfonic acid (TFMS) in tertiary butanol $(0.1 \mathrm{M})$ and tetrabutyl ammonium hydroxide (TBuAOH) in isopropanol/ methanol $(0.1 \mathrm{M})$. For the $\mathrm{NH}_{2}$ endgroup detection, the PBTA was dissolved in phenol/water $(85 / 15 \mathrm{vol} \%)$ and directly titrated with TFMS. For the $\mathrm{COOH}$ endgroup detection, about $100 \mathrm{mg}$ PBTA was dissolved in $2 \mathrm{ml}$ of 1,1,1,3,3,3-hexafluoro-2-propanol and diluted with $9 \mathrm{ml}$ trifluoroethanol. First a certain volume of $\mathrm{TBuAOH}$ was added, followed by a backtitration with TFMS. Comparison of the reference with the first equivalency point (e.p.) results in the $\mathrm{COOH}$ content, and with the second e.p. yields the 'total base' (usually $\mathrm{NH}_{2}$ ). 


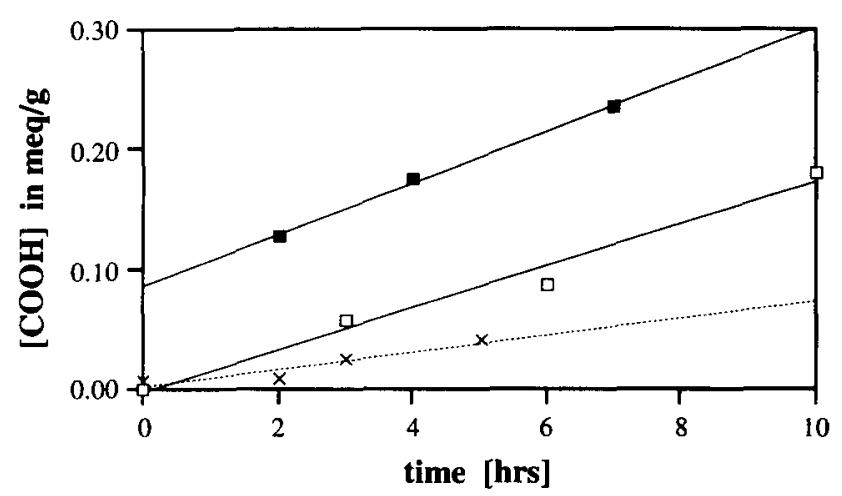

Figure $3 \mathrm{COOH}$ concentration versus time for $\mathrm{PBT}$ : $\times, 255^{\circ} \mathrm{C}$ / vacuum; $\square, 270^{\circ} \mathrm{C} / \mathrm{N}_{2} ; \mathbf{\square}, 270^{\circ} \mathrm{C} /$ vacuum

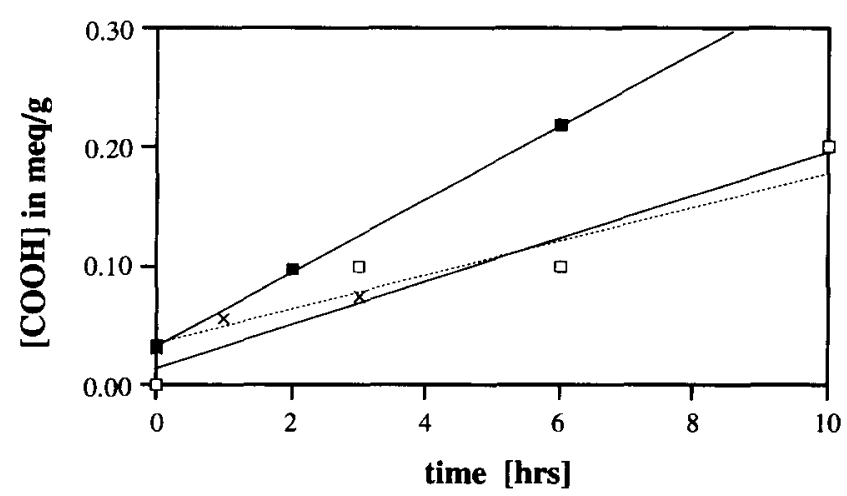

Figure $4 \mathrm{COOH}$ concentration versus time for PBTA20: $\times, 255^{\circ} \mathrm{C} /$ vacuum; $\square, 270^{\circ} \mathrm{C} / \mathrm{N}_{2} ; \mathbf{D}, 270^{\circ} \mathrm{C} /$ vacuum

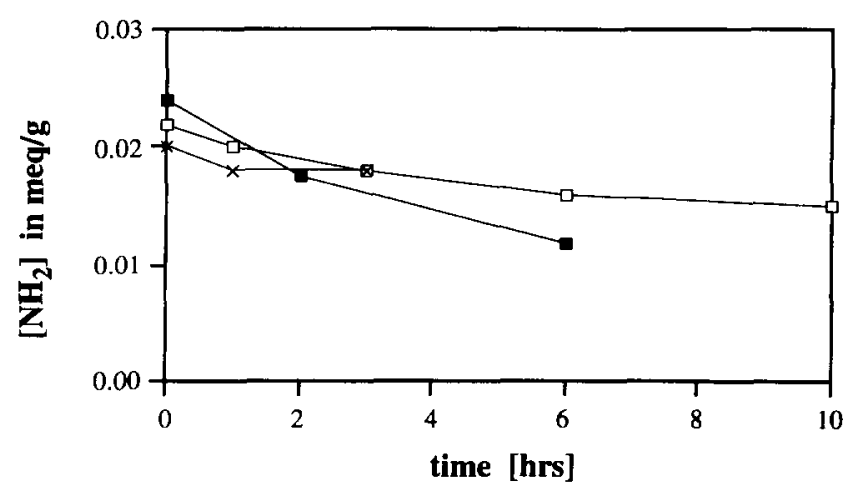

Figure $5 \mathrm{NH}_{2}$ concentration versus time for $\mathrm{PBTA20:} \times, 255^{\circ} \mathrm{C}$ vacuum; $\square, 270^{\circ} \mathrm{C} / \mathrm{N}_{2} ; \mathbf{\square}, 270^{\circ} \mathrm{C} /$ vacuum

\section{RESULTS AND DISCUSSION}

\section{Molecular weight decrease}

Figures 1 and 2 show the change in inherent viscosity $\left(\eta_{\text {inh }}\right)$ of PBT and PBTA20 as a result of prolonged reaction in the molten state at 255 and $270^{\circ} \mathrm{C}$. The degradation tests 'started' at time zero with polymers synthesized under standard conditions $\left(1 \mathrm{~h}\right.$ at $255^{\circ} \mathrm{C}$ and reduced pressure). The PBT samples show a considerable variation in initial $\eta_{\text {inh }}$. This has to be ascribed to small differences in applied vacuum, stirring efficiency and exact oil bath temperature. PBT $\left(255^{\circ} \mathrm{C} /\right.$ vacuum) and $\mathrm{PBT}\left(270^{\circ} \mathrm{C} /\right.$ vacuum $)$ had a maximum value of $\eta_{\text {inh }}$ after $2 \mathrm{~h}$. The viscosities were lower for the series at $270^{\circ} \mathrm{C}$. The PBTA20 samples in Figure 2 show a more consistent behaviour. The attained maximum viscosities for PBTA are lower. The series at $270^{\circ} \mathrm{C}$ had lower viscosities than the series at $255^{\circ} \mathrm{C}$.

The viscosity changes suggest the simultaneous occurrence of condensation and degradation reactions in the experiments. Furthermore, the final value of $\eta_{\text {inh }}$, attained after about $10 \mathrm{~h}$ at $270^{\circ} \mathrm{C}$, appeared to be about the same for PBT and PBTA20, irrespective of the difference in the $\eta_{\text {inh }}$ at time zero.

\section{Formation of $\mathrm{COOH}$ and $\mathrm{NH}_{2}$ endgroups}

The formation of carboxylic acid $(\mathrm{COOH})$ endgroups during prolonged reaction in the melt is shown in Figures 3 and 4 . The degradation rate of PBT in vacuo or $\mathrm{N}_{2}$ atmosphere was characterized by a gradual increase of $\mathrm{COOH}$ endgroups with time (Figure 3). For $\mathrm{PBT}$, the formation of $\mathrm{COOH}$ groups via $\beta$-elimination is a first-order process ${ }^{9}$. Our data suggest a first-order degradation process too. Pilati et al. ${ }^{7}$ supposed that the linear relation of $\mathrm{COOH}$ formation with time excluded a possible (auto)catalytic effect of the acid. Other authors, however, reported the catalysis of degradation reactions by added acid compounds 10,12 .

The formation of $\mathrm{COOH}$ endgroups in PBTA20 took place at about the same rate as observed for PBT (Figure 4). This suggests that chain cleavage in PBTA20 occurred preferentially at the ester linkage. The application of vacuum increased the degradation rate compared with that in $\mathrm{N}_{2}$ atmosphere. The stripping of lowmolecular-weight products such as THF, butadiene and pyrrolidine was probably promoted by the lowered vapour pressure.

The concentration of $\mathrm{NH}_{2}$ endgroups in PBTA20 decreased slowly with reaction time during the experiments at $255^{\circ} \mathrm{C}$ in vacuo and at $270^{\circ} \mathrm{C}$ in $\mathrm{N}_{2}$ (Figure 5). At $270^{\circ} \mathrm{C}$ in vacuo the $\mathrm{NH}_{2}$ content in PBTA20 decreased more strongly with increasing time. The number of $\mathrm{NH}_{2}$ endgroups may have been reduced by its cyclization into pyrrolidine endgroups or by its amidation with $\mathrm{COOH}$ endgroups. It cannot be excluded that new $\mathrm{NH}_{2}$ endgroups are formed via hydrolysis or alcoholysis of amides. Apparently, these reactions occurred at a lower rate. Thermal degradation of amides would result in weak basic primary amide endgroups $\mathrm{CONH}_{2}$ [reaction (7a)] which have not been determined. All these reactions seemed to be of minor importance owing to the low $\mathrm{NH}_{2}$ content compared with the $\mathrm{COOH}$ content (Figure 5 versus Figure 4).

\section{Degradation kinetics}

Passalacqua et al..$^{9}$ and Deveaux et al. ${ }^{11}$ reported two methods to analyse the thermal degradation behaviour of PBT. The degradation rate constant (of the $\beta$-elimination) could be determined from the change in viscosity and from the change in $\mathrm{COOH}$ endgroup content upon increasing time. We assumed for PBTA that condensation reactions (esterification and amidation) could be neglected compared with the $\beta$-elimination of ester bonds.

Viscometry. The thermal degradation of a structural ester unit consists of two subsequent ester cleavages with rate constants $k_{1}$ and $k_{2}$ [reactions (4a) and (4b)]. Passalacqua et $a l^{9}{ }^{9}$ supposed that the primary ester cleavage was the rate-determining step with respect to 
the number-average degree of polymerization $\left(\overline{X_{\mathrm{n}}}\right)$, thus $k_{2} \gg k_{1}$. These authors used a kinetic treatment of the Tuckett type ${ }^{32}$ which resulted in a linear relationship between $1 / \overline{X_{\mathrm{n}}}$ and time $t$ [equation (8)], on the condition that $\overline{X_{\mathrm{n}}} \gg 1$. Deveaux et al. ${ }^{\mathrm{II}}$, on the other hand, used a calculation method developed by Casassa ${ }^{33}$ for the statistic degradation of polymers, taking into account the possibility of two ester cleavages per structural unit. By assuming a first-order reaction, Deveaux et al. also obtained equation (8). This indicated that the degradation rate constant $k_{1}$ is independent of the ester concentration in the polymer. Therefore, a correction for the ester content in PBTA20 has not been applied.

$$
\frac{1}{\overline{X_{\mathrm{n}}}(t)}=\frac{1}{\overline{X_{\mathrm{n}}}(0)}+k_{1} t
$$

The number-average degree of polymerization $\overline{X_{\mathrm{n}}}$ (or

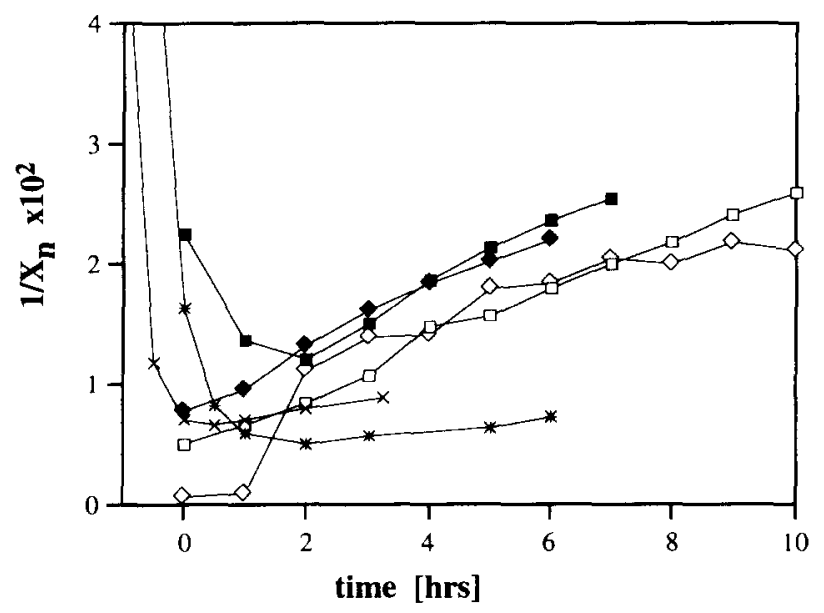

Figure 6 Reciprocal $\overline{X_{\mathrm{n}}}$ from viscosity data versus time for PBT $\left(*, 255^{\circ} \mathrm{C} /\right.$ vacuum; $\square, 270^{\circ} \mathrm{C} / \mathrm{N}_{2} ; \mathbf{\square}, 270^{\circ} \mathrm{C} /$ vacuum) and PBTA20 ( $\times, 255^{\circ} \mathrm{C} /$ vacuum; $\diamond, 270^{\circ} \mathrm{C} / \mathrm{N}_{2} ; \diamond 270^{\circ} \mathrm{C} /$ vacuum $)$
$\left.\overline{M_{\mathrm{n}}} / M_{0}\right)$ of PBT and PBTA20 has been calculated from the inherent viscosity measured in phenol/1,1,2,2-tetrachloroethane $(36 / 64 \mathrm{wt} \%)$ at $25^{\circ} \mathrm{C}$. We used a MarkHouwink relation [equation (9)], reported by Deveaux et al. ${ }^{\text {I }}$, which was valid for phenol/1,1,2,2-tetrachloroethane $(60 / 40 \mathrm{wt} \%)$ at $25^{\circ} \mathrm{C}$ :

$$
[\eta]=2.15 \times 10^{-4} \bar{M}_{\mathrm{n}}^{0.82}
$$

The intrinsic viscosity $[\eta]$ was calculated from the inherent viscosity $\eta_{\text {inh }}$ with the one-point method of Raju and Yaseen ${ }^{34}$ [equation (10)]. The concentration $c$ was $0.5 \mathrm{~g} \mathrm{dl}^{-1}$ and the relative viscosity was calculated from $\ln \eta_{\text {rel }}=c \times \eta_{\text {inh }}$. When $\eta_{\text {rel }}<1.3, K$ is 0.14 and when $1.3<\eta_{\text {rel }}<1.8 K$ is 0.12

$$
\log [\eta]=\log \left(\frac{\eta_{\text {rel }}-1}{c}\right)-K\left(\eta_{\text {rel }}-1\right)
$$

The difference in $[\eta]$ determined by extrapolation of $\eta_{\text {inh }}$ to zero concentration with $[\eta]$ via Raju and Yaseen remained within $3 \% . \overline{X_{\mathrm{n}}}(0)$ has been taken at the time when the maximum value of viscosity was attained.

In Figure 6 the reciprocal of $\overline{X_{\mathrm{n}}}$ derived from the viscosity data is presented as a function of the degradation time at 255 or $270^{\circ} \mathrm{C}$. Initially the molecular weight is increased. At longer reaction times degradation is the main mechanism. From the slopes of these the degradation rates can be calculated (Table 2).

Endgroup calculations. Passalacqua et al. ${ }^{9}$ also described a method to determine the number-average degree of polymerization $\left(\overline{X_{n}}\right)$, by endgroup measurements. Per ester repeat unit two subsequent $\beta$-eliminations are possible, but it was again assumed that the elimination of butadiene from the unsaturated 3-butenyl ester endgroup occurs at a higher rate than the primary ester cleavage $\left(k_{2} \gg k_{1}\right)$. With a steady-state approximation for the 3-butenyl ester endgroup, Passalacqua obtained equation (11), in which $[N$ ester linkages $]=$ mol ester

\begin{tabular}{|c|c|c|c|c|c|}
\hline Polymer & $\begin{array}{l}T \\
\left({ }^{\mathrm{C}}\right)\end{array}$ & Conditions & $\begin{array}{l}k_{1}\left(10^{-7} \mathrm{~s}^{-1}\right) \\
\text { [viscometry] }\end{array}$ & $\begin{array}{l}k_{1}\left(10^{-7} \mathrm{~s}^{-1}\right) \\
{[\mathrm{COOH} \text { meas. }]}\end{array}$ & Ref. \\
\hline PBT & 255 & vacuum/stirred & 1.5 & 2.2 & - \\
\hline PBT & 270 & $\mathrm{~N}_{2} /$ stirred & 6.0 & 5.2 & - \\
\hline PBT & 270 & vacuum/stirred & 7.6 & 6.4 & - \\
\hline PBTA20 & 255 & vacuum/stirred & 2.3 & 4.6 & - \\
\hline PBTA20 & 270 & $\mathrm{~N}_{2} /$ stirred & 5.1 & 5.5 & - \\
\hline PBTA20 & 270 & vacuum/stirred & 6.9 & 9.5 & \\
\hline PBT & 260 & vacuum/sealed & 8.4 & 8.4 & 9 \\
\hline PBT & 280 & vacuum/sealed & 37.1 & 34.5 & 9 \\
\hline PBT & 253 & $\mathrm{~N}_{2} /$ rheometer & 9.1 & - & 11 \\
\hline PBT & 267 & $\mathrm{~N}_{2} /$ rheometer & 26.8 & & 11 \\
\hline PHT $^{\mathrm{a}}$ & 260 & $\mathrm{~N}_{2} /$ stirred & 6.0 & - & 36 \\
\hline $\mathrm{PHT}^{\mathrm{a}}$ & 280 & $\mathrm{~N}_{2} /$ stirred & 17.1 & 16.9 & 36 \\
\hline $6 \mathrm{NT} 6^{\mathrm{b}}$ & 260 & vacuum/sealed & 21.0 & - & 21 \\
\hline $6 \mathrm{NT} 6^{\mathrm{b}}$ & 280 & vacuum/sealed & 86.1 & - & 21 \\
\hline
\end{tabular}

Table 2 Degradation rate constants $k_{1}$ of PBT and PBTA20 compared with those of PBT, PHT and 6NT6, determined by viscometry and endgroup analysis

a Poly(hexamethylene terephthalate)

${ }^{\mathrm{b}}$ Alternating poly(ester amide) based on PHT 


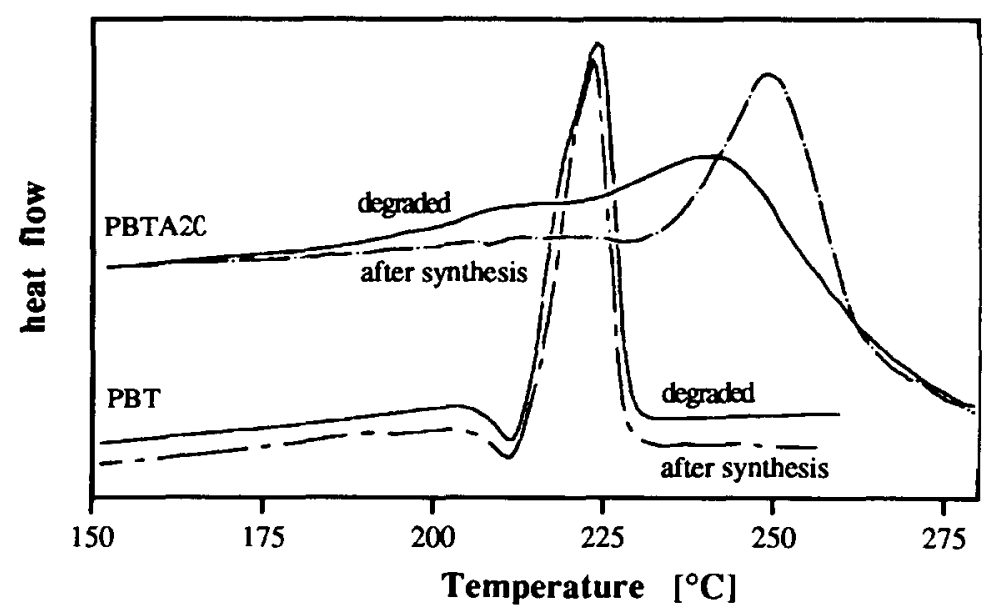

Figure 7 D.s.c. scan, second heating, of PBT and PBTA20 directly after synthesis $(0 \mathrm{~h})$ and after $7 \mathrm{~h}$ at $270^{\circ} \mathrm{C} /$ vacuum

Table 3 Thermal properties and amide block fraction in PBTA20 as a function of degradation time

\begin{tabular}{lccll}
\hline $\begin{array}{l}\text { Temperature and } \\
\text { atmosphere }\end{array}$ & $\begin{array}{l}\text { Time } \\
(\mathrm{h})\end{array}$ & $\begin{array}{c}X_{\mathrm{AA}} / X_{\mathrm{A}} \\
(\mathrm{mol} \%)\end{array}$ & $\begin{array}{l}T_{\mathrm{m} 2}{ }^{\mathrm{a}} \\
\left({ }^{\circ} \mathrm{C}\right)\end{array}$ & $\begin{array}{l}T_{\mathrm{c}} \\
\left({ }^{\circ} \mathrm{C}\right)\end{array}$ \\
\hline $255^{\circ} \mathrm{C}$ in vacuo & 1 & 3.3 & $222+\underline{250}$ & 215 \\
$255^{\circ} \mathrm{C}$ in vacuo & 4 & 10.4 & $225+\underline{246}$ & 217 \\
$270^{\circ} \mathrm{C}$ in vacuo & 0 & 5.1 & $225+\underline{251}$ & 217 \\
$270^{\circ} \mathrm{C}$ in vacuo & 6 & 28.6 & $212+\underline{238}$ & 203 \\
$270^{\circ} \mathrm{C}$ in vacuo & 10 & 33.1 & $195+\underline{226}$ & 196 \\
$270^{\circ} \mathrm{C}$ in $\mathrm{N}_{2}$ & 0 & 6.7 & $224+\underline{248}$ & 218 \\
$270^{\circ} \mathrm{C}$ in $\mathrm{N}_{2}$ & 10 & 23.7 & $212+\underline{234}$ & 204 \\
\hline
\end{tabular}

${ }^{a}$ The main peak is underlined

linkages $/ \mathrm{mol}$ repeat units and $[N .(\mathrm{COOH})]=\mathrm{mol}$ of $\mathrm{COOH}$ endgroups $/ \mathrm{mol}$ repeating units $(0 \leq \mathrm{N} \leq 2)$ :

$$
\frac{\mathrm{d}[N \cdot(\mathrm{COOH})]}{\mathrm{d} t}=k_{1}[N \text { ester linkages }]
$$

According to Passalacqua et al., this relation should result in a linear increase of the number of $\mathrm{COOH}$ endgroups with time. This was verified for the degradation of PBT over a temperature range of $240-280^{\circ} \mathrm{C}$. However, the authors did not present their integrated equation. We adjusted equation (11) to our experiments with $N^{*}=N / 2$ because two carboxylic acid endgroups are formed per ester repeating unit. [COOH], in $\mathrm{mol} / \mathrm{mol}$ repeating unit, is the measured $\mathrm{COOH}$ endgroup concentration in meq $\mathrm{g}^{-1}$ polymer multiplied by the weight of the repeating unit $M_{0}$ :

$$
\frac{\mathrm{d}[\mathrm{COOH}]}{\mathrm{d} t}=2 k_{\mathrm{l}}\left[N^{*} \text { ester repeating units }\right]
$$

In the case of high molecular weight $\left(\overline{X_{n}} \gg 1\right)$, the concentration of ester repeating units is assumed to be constant. The number of $\mathrm{COOH}$ endgroups must be found to increase linearly with time:

$$
[\mathrm{COOH}]_{t}=[\mathrm{COOH}]_{0}+2 k_{1} t
$$

The linearity was also verified for our degradation experiments of PBT (Figure 3) and PBTA20 (Figure 4). In the case of autocatalysis, the concentration of $\mathrm{COOH}$ endgroups would increase exponentially with increasing degradation time. Pitt and $\mathrm{Gu}^{35}$ studied the hydrolysis of polyesters and reported a logarithmic type of relation for autocatalysis by the generated $\mathrm{COOH}$ endgroups as follows:

$$
\ln [\mathrm{COOH}]=\ln [\mathrm{COOH}]_{0}+2 k_{1} t
$$

However, as expected ${ }^{9}$, the exponential dependence of [COOH] with time has not been observed for PBT and PBTA20 (Figures 3 and 4 respectively). This indicates that the $\beta$-elimination in PBT and PBTA20 has not been catalysed by the generated $\mathrm{COOH}$ endgroups.

Degradation constants. The degradation rate constant $k_{1}$ from viscosity measurements (Figure 6 ) and $k_{1}$ from $\mathrm{COOH}$ endgroup measurements (Figures 3 and 4 ) were calculated from the slopes via a least-squares linearization. In Table 2 the results for PBT and PBTA20 have been compared with literature data for PBT, PHT [poly(hexamethylene terephthalate)] and alternating poly(ester amide) 6NT6.

A comparison of the measured rate constants for PBT and PBTA20 shows good agreement between $k_{1}$ based on viscosity changes and $k_{1}$ based on $\mathrm{COOH}$ endgroups (Table 2). This affirms the reliability of the used kinetic theories for PBTA20, despite difficulties in endgroup measurement (e.g. solubility of highly degraded polymers) and the use of an approximation in the calculation of $\overline{X_{n}}$ from the inherent viscosity.

Our degradation rate constants for PBT were of the same order of magnitude as the values reported by Passalacqua et al. ${ }^{9}$ and Deveaux et al. ${ }^{11}$, but appeared to be somewhat lower. This can partly be ascribed to the above-mentioned experimental difficulties. A more important explanation is the difference in type of reaction set-up. Passalacqua et al. determined the degradation rate of PBT in a glass ampoule placed in an oven with an accurate temperature control $\left( \pm 1^{\circ} \mathrm{C}\right)$. Deveaux et al., on the other hand, used a capillary rheometer at $550 \mathrm{~s}^{-1}$ with presumably good heat transfer in the barrel. However, the degradation studies described in this paper were carried out in glass flask immersed in an oil bath. The oil bath temperature was controlled. As the rate constant depends strongly on temperature, the lower degradation rate might have been caused by a lower reaction temperature in the mixture than the actual oil bath temperature. 


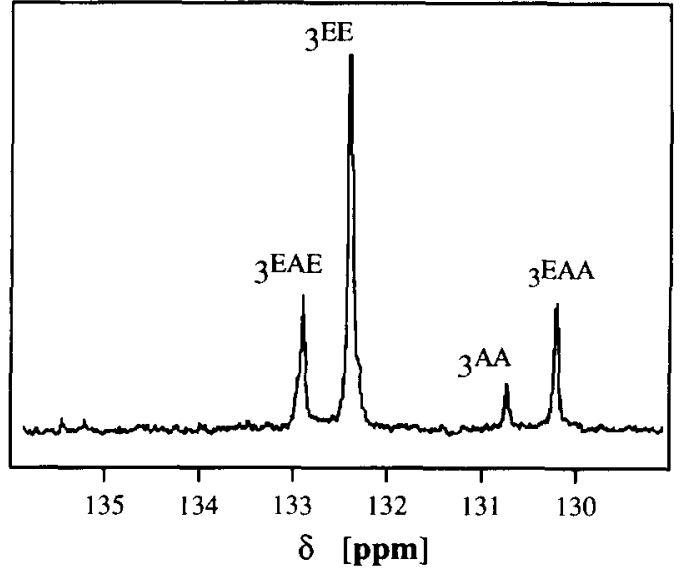

Figure 8 Example of a ${ }^{13} \mathrm{C}$ n.m.r. scan of degraded PBTA20 (10 h at $270^{\circ} \mathrm{C} / \mathrm{N}_{2}$ ) with a relative amide block fraction $X_{\mathrm{AA}} / X_{A}$ of $23.7 \%$

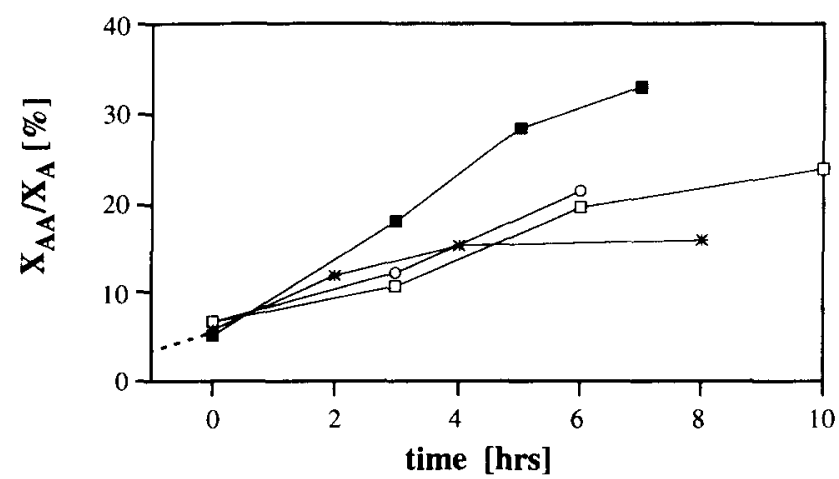

Figure 9 Relative amide block fraction versus time for PBTA20 $*, 255^{\circ} \mathrm{C} /$ vacuum; $\square, 270^{\circ} \mathrm{C} / \mathrm{N}_{2} ; \bigcirc, 270^{\circ} \mathrm{C} /$ vacuum; $\mathbf{\square}, 275^{\circ} \mathrm{C} /$ vacuum

Furthermore, it appeared that PBTA20 showed a higher degradation rate at $255^{\circ} \mathrm{C}$ in vacuo than PBT (Table 2). The degradation rate constants of PBT or PBTA20 at $270^{\circ} \mathrm{C}$ (in vacuo and in $\mathrm{N}_{2}$ ) were about equal. Apparently, the introduction of amides did not decrease the thermal stability of PBT which is in contradiction with the experiments of Pilati et al. ${ }^{21}$.

Pilati et al. ${ }^{21}$ measured for the poly(ester amide) 6 NT6 a considerably higher degradation rate than for the polyester PHT $^{36}$ and concluded that amide groups in a terephthalic para position to ester groups destabilized the ester bond. It is admitted that 6NT6 contains a higher amide content $(50 \mathrm{~mol} \%)$ than PBTA20 and, as discussed above, the test method and duration differed. Thermal treatment of $6 \mathrm{NT} 6$ at $260^{\circ} \mathrm{C}$ (close (negative) effect of the presence of amide groups on the thermal stability of ester groups. Still unexplained is the fact that PBTA has a lower maximum viscosity than PBT.

\section{Thermal properties}

The effect of thermal degradation on the melting behaviour of PBT and PBTA20 has been studied by d.s.c. (Figure 7). The melting temperature of PBT after $7 \mathrm{~h}$ at $270^{\circ} \mathrm{C}$ in vacuo appeared not to be affected by thermal degradation. This was also observed for PBT, degraded at $255^{\circ} \mathrm{C}$ in vacuo. However, the crystallization temperature $\left(T_{\mathrm{c}}\right)$ and enthalpy $\left(\Delta H_{\mathrm{c}}\right)$ of PBT increased with degradation time. This indicates that the crystallization rate of PBT was increased due to its lower molecular weight.

The thermal behaviour of PBTA20 was clearly affected by the prolonged residence time in the melt. The melting peak of PBTA20 broadened and the melting temperature decreased with increasing reaction time at $270^{\circ} \mathrm{C}$ in vacuo (Figure 7). Surprisingly, the crystallization temperature of PBTA20 also decreased gradually with increasing degradation time in the melt (Table 3). The rate of crystallization appeared to be decreased in spite of the lowered inherent viscosity of PBTA20. However, the enthalpy of crystallization $\left(\Delta H_{\mathrm{c}}\right)$ and the enthalpy of melting $\left(\Delta H_{\mathrm{m}}\right)$ were less affected by thermal degradation.

\section{Ester-amide interchange}

The chain structures of the degraded PBTA20 samples were analysed by ${ }^{13} \mathrm{C}$ n.m.r. The scans revealed an increase of amide block fraction $X_{\mathrm{AA}} / X_{\mathrm{A}}$ with degradation time. Apparently, ester-amide interchange had occurred at high temperature in the melt. Owing to a randomization of the ester and amide units, the degree of uniformity of the amide segment in PBTA20 decreased. Table 3 shows that the melting temperature of PBTA20 decreased with an increasing amide block fraction.

Sequential analysis of ester/amide triads. The sequential analysis of PBTA was based on terephthalic carbons $\left(3^{i j}\right)$. These carbons showed single peaks in a ${ }^{13} \mathrm{C}$ n.m.r. scan with a chemical shift depending on the ester or amide neighbouring group (Figure 8). The calculation was analogous to that of Yamadera and Muran ${ }^{37}$ and was based on three types of ester-amide triad, i.e. ester-ester, ester-amide and amide-amide:

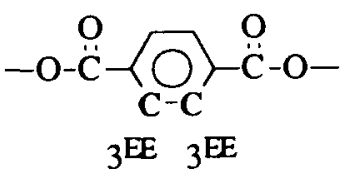

to its melting temperature, $258^{\circ} \mathrm{C}$ ) and at $280^{\circ} \mathrm{C}$ resulted, after only $1 \mathrm{~h}$, in incomplete solubility and amide block formation. Pilati et al. also assumed the occurrence of branching or crosslinking of $6 \mathrm{NT} 6$. We observed in the experiments with PBTA no significant

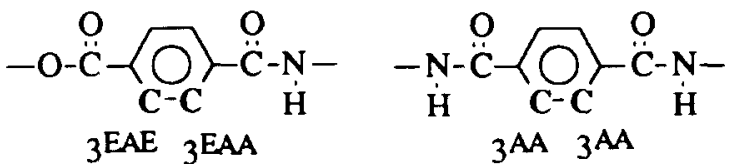

The mole fractions $X_{\mathrm{EE}}, X_{\mathrm{EA}}$ and $X_{\mathrm{AA}}$ of the respective triads were obtained by integration of the type 3 carbons. The probabilities of triad AE and triad EA were assumed to be equal: $X_{\mathrm{AE}}=X_{\mathrm{EA}}$. This was experimentally verified by comparison of the corresponding integrated carbon 
peaks $3^{\mathrm{EAE}}$ and $3^{\mathrm{EAA}}$.

$$
\begin{aligned}
X_{\mathrm{EE}} & =3^{\mathrm{EE}} / 3^{\text {total }} \\
X_{\mathrm{EA}} & =\left(3^{\mathrm{EAE}}+3^{\mathrm{EAA}}\right) / 3^{\text {total }} \\
X_{\mathrm{AA}} & =3^{\mathrm{AA}} / 3^{\text {total }}
\end{aligned}
$$

The mole fractions $X_{\mathrm{E}}$ and $X_{\mathrm{A}}$ of ester and amide groups with respect to the total number of ester and amide groups are defined in equations (18) and (19). $X_{\mathrm{E}}$ and $X_{\mathrm{A}}$ represent the ester and amide content, respectively, in PBTA and should equal 0.8 and 0.2 for PBTA20.

$$
\begin{aligned}
& X_{\mathrm{E}}=\left(3^{\mathrm{EAE}}+3^{\mathrm{EE}}\right) / 3^{\text {total }} \\
& X_{\mathrm{A}}=\left(3^{\mathrm{EAA}}+3^{\mathrm{AA}}\right) / 3^{\text {total }}
\end{aligned}
$$

As a consequence, the relative amide block fraction, a

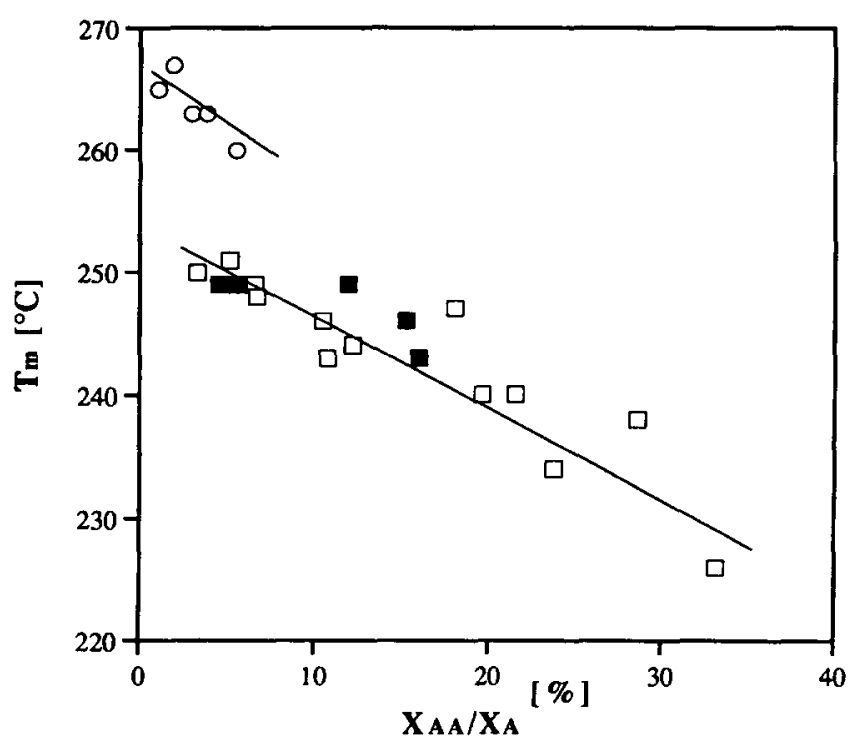

Figure 10 Melting temperature versus relative amide block fraction $X_{\mathrm{AA}} / X_{\mathrm{A}}:$ O, T4T.dimethyl (first scan); $\square$, PBTA20 (second scan); 口, PBTA20 \# (degraded, second scan) measure for the uniformity of the amide segment in the polyesteramide, can be defined as:

$$
\frac{X_{\mathrm{AA}}}{X_{\mathrm{A}}}=\frac{3^{\mathrm{AA}}}{3^{\mathrm{AA}}+3^{\mathrm{EAA}}} \times 100
$$

Rate of ester-amide interchange. The degree of ester-amide interchange in PBTA20 is represented by the relative amide block fraction $X_{\mathrm{AA}} / X_{\mathrm{A}}$. In addition, the rate of interchange is given by the slope of a curve of $X_{\mathrm{AA}} / X_{\mathrm{A}}$ versus time. Figure 9 clearly shows a more or less linear increase of amide block formation with increasing time in a stirred PBTA melt. The $X_{\mathrm{AA}} / X_{\mathrm{A}}$ of PBTA20 directly after polymerization (time zero) was determined by the purity of T4T.dimethyl and by ester-amide interchange during the polymerization. Extrapolation of the $X_{\mathrm{AA}} / X_{\mathrm{A}}$ curve to $1 \mathrm{~h}$ (Figure 9) yields the amide block fraction in the non-uniform T4T.dimethyl.

The rate of ester-amide interchange shows an increase with rising temperature from 255 to $275^{\circ} \mathrm{C}$. As expected, the atmosphere in the reactor (nitrogen flow or reduced pressure) had little effect on the rate of interchange.

Titanate compounds might have had a catalytic effect on the ester-amide interchange, analogous to the catalysis of ester-ester interchange. In one experiment, a high amount of $\mathrm{Ti}\left(\mathrm{OC}_{3} \mathrm{H}_{7}\right)_{4}(500 \mathrm{ppm} \mathrm{Ti})$ was used for the synthesis of PBTA20. The $X_{\mathrm{AA}} / X_{\mathrm{A}}$ of this polymer after $1 \mathrm{~h}$ at $255^{\circ} \mathrm{C}$ was $4.6 \%$. This amide block fraction is not higher than that in PBTA20 synthesized with $120 \mathrm{ppm} \mathrm{Ti}$. Apparently, a larger amount of titanates did not accelerate the ester-amide interchange reaction.

\section{Influence of amide uniformity on $\mathrm{T}_{m}$ of T4T.dimethyl and PBTA20}

The melting temperatures of samples of T4T.dimethyl and PBTA20 have been related to their relative amide block fraction $X_{\mathrm{AA}} / X_{\mathrm{A}}$ (Figure 10 ). The $T_{\mathrm{m}}$ of lowmolecular-weight T4T.dimethyl and of PBTA20 appeared to decrease with increasing $X_{\mathrm{AA}} / X_{\mathrm{A}}$, thus with decreasing uniformity of the amide segment. It has been demonstrated that the melting peak of T4T.dimethyl and PBTA20 broadened with decreasing

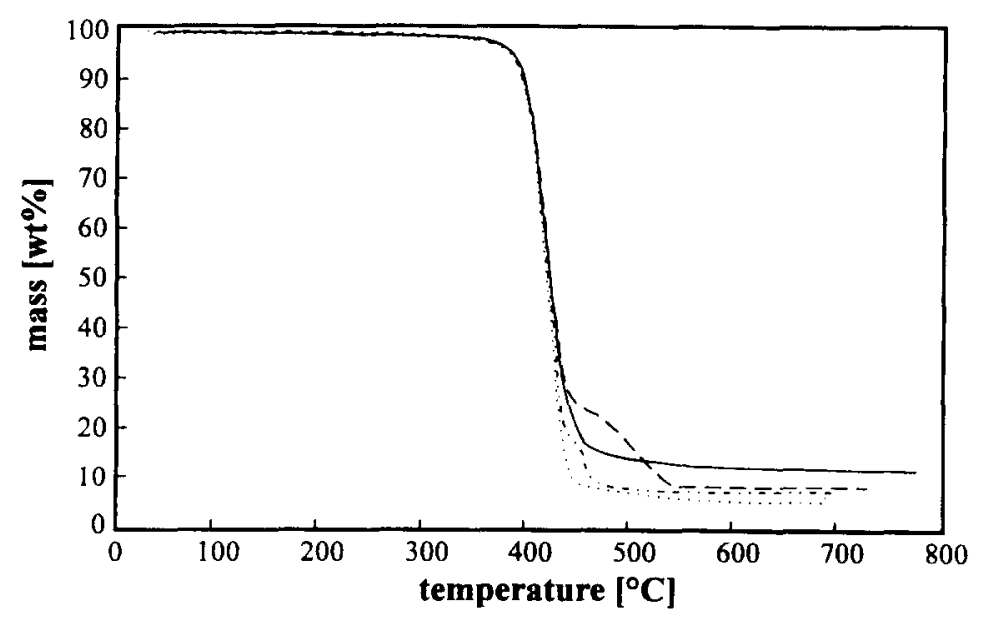

Figure 11 T.g.a. at $10^{\circ} \mathrm{Cmin}^{-1}: \ldots$, PBT in $\mathrm{N}_{2} ; \cdot \ldots \ldots$, PBT in air; - - PBTA20 in $\mathrm{N}_{2} ;-\cdots,-$, PBTA20 in air 


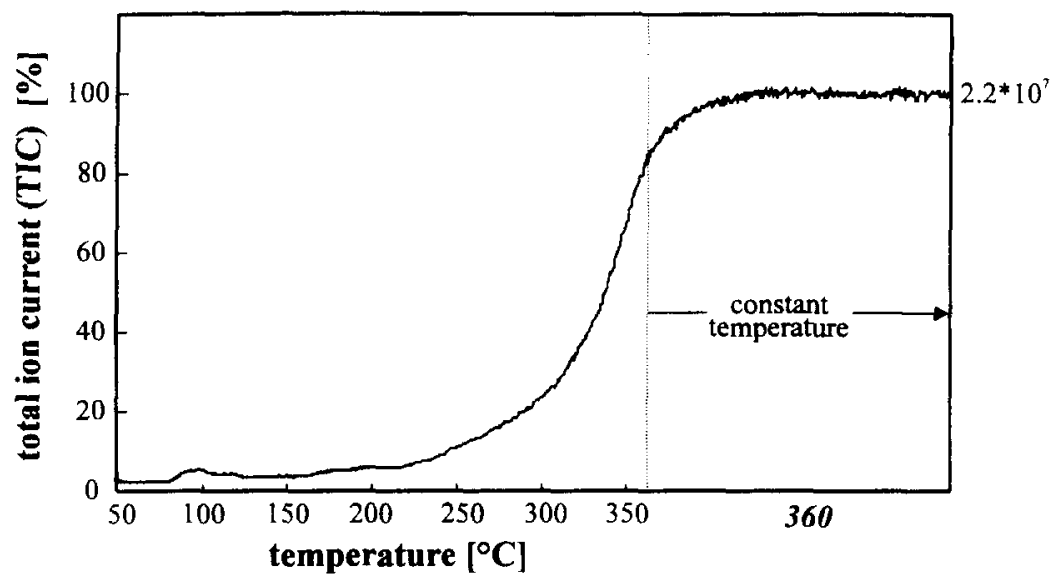

Figure 12 Total ion current of PBTA20 versus probe temperature (DP-m.s., $10 \mathrm{C} \mathrm{min}^{-1}$ )

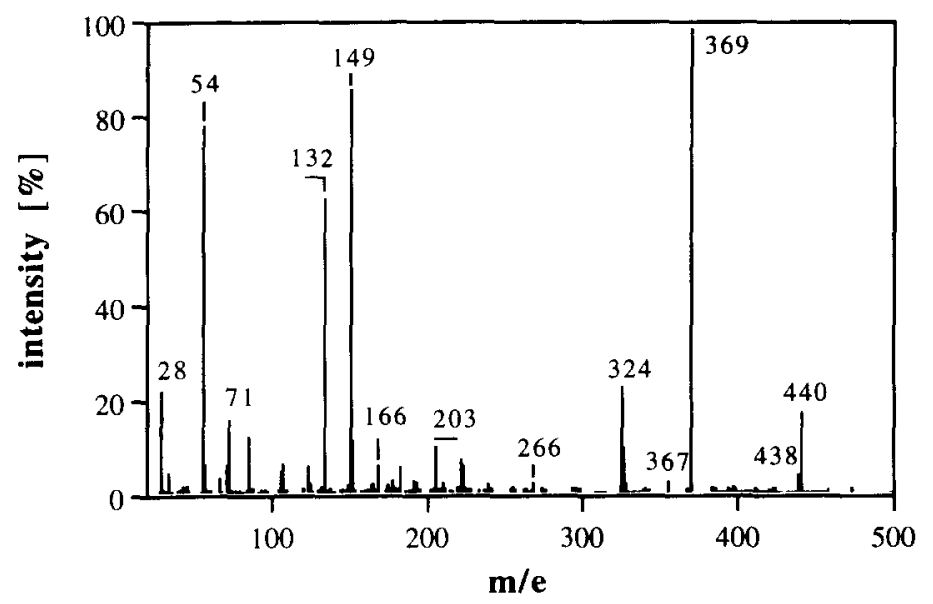

Figure 13 Mass spectrum at $300^{\circ} \mathrm{C}$ of PBTA20 (DP-m.s. with $18 \mathrm{eV}$ )

Table 4 Decomposition temperatures of PBT and PBTA20 from t.g.a. measurements in nitrogen and air atmosphere (heating rate of $\left.10^{\circ} \mathrm{C} \mathrm{min}^{-1}\right)$

\begin{tabular}{lclll}
\hline Polymer & $\begin{array}{l}\text { Li content } \\
(\mathrm{ppm})\end{array}$ & Atmosphere & $\begin{array}{l}\text { LDT } \\
\left({ }^{\circ} \mathrm{C}\right)\end{array}$ & $\begin{array}{l}\text { ADT } \\
\left({ }^{\circ} \mathrm{C}\right)\end{array}$ \\
\hline PBT & 0 & $\mathrm{~N}_{2}$ & 395 & 420 \\
& & air & 392 & 416 \\
PBTA20 & 6 & $\mathrm{~N}_{2}$ & 394 & 420 \\
& & air & 388 & 420 \\
PBTA20 & 250 & $\mathrm{~N}_{2}$ & 396 & 420 \\
& & air & 388 & 420 \\
Nylon-4,T & 0 & $\mathrm{~N}_{2}$ & - & $470^{\mathrm{b}}$ \\
& $+\mathrm{Na}$ benzoate & $\mathrm{N}_{2}$ & - & $420^{\mathrm{b}}$ \\
\hline
\end{tabular}

${ }^{a}$ With extra $\mathrm{LiOCH}_{3}$ during the T4T.dimethyl synthesis

${ }^{b}$ From Ballistreri et $a l^{31}$

uniformity ${ }^{6}$. The peak maximum of the broader peaks was located at a lower temperature.

Probably, the longer amide blocks in T4T.dimethyl and PBTA20 have disturbed the crystalline order in a similar manner. PBTA20 with $X_{\mathrm{AA}} / X_{\mathrm{A}}$ of $33 \%(10 \mathrm{~h}$ degradation at $270^{\circ} \mathrm{C}$ ) has been studied by X-ray diffraction. The diffractogram of degraded PBTA20 revealed broader peaks than those in the diffractogram of PBTA20 measured directly after synthesis $\left(X_{\mathrm{AA}} / X_{\mathrm{A}}\right.$ of about $5 \%)^{38}$. This indicates that less uniform diamide units result in less perfect lamellae.

\section{T.g.a. measurements}

The thermal stability of PBT and PBTA20 has also been investigated by t.g.a. The rate of volatilization was followed at a heating rate of $10^{\circ} \mathrm{C} \mathrm{min}^{-1}$ and the decomposition temperatures of PBT and PBTA20 were compared in an atmosphere of $\mathrm{N}_{2}$ and air (Figure 11 and Table 4).

Based on the measured weight loss, PBT and PBTA20 show about the same lower and average decomposition temperatures (LDT and ADT) when heated to $800^{\circ} \mathrm{C}$. This indicates equal rates of decomposition for PBT and PBTA20. The atmosphere during decomposition, $\mathrm{N}_{2}$ or air, had no effect on the LDT and ADT of both polymers. Thus thermo-oxidative degradation has little effect on the initial weight loss.

PBT differed from PBTA20 in the last stage of the thermal degradation process (Figure 12). In $\mathrm{N}_{2}$ PBT had no residue after decomposition whereas PBTA20 had a residue of about $10 \%$. In air PBT and PBTA20 decomposed completely, although the upper decomposition temperature (UDT) of PBTA20 was higher than that of PBT. For practical applications, the LDT is a more important parameter than the UDT. Any decomposition can have a large effect on polymer properties.

The effect of lithium catalyst residues on the thermal stability of PBTA20 has been studied by degradation of PBTA $20^{\mathrm{a}}$. In one experiment extra $\mathrm{LiOCH}_{3}$ was added 
Table 5 Main thermal degradation products of PBT determined by EI-DP m.s. ${ }^{40}$ and of nylon-4,T determined by chemical ionization mass spectrometry

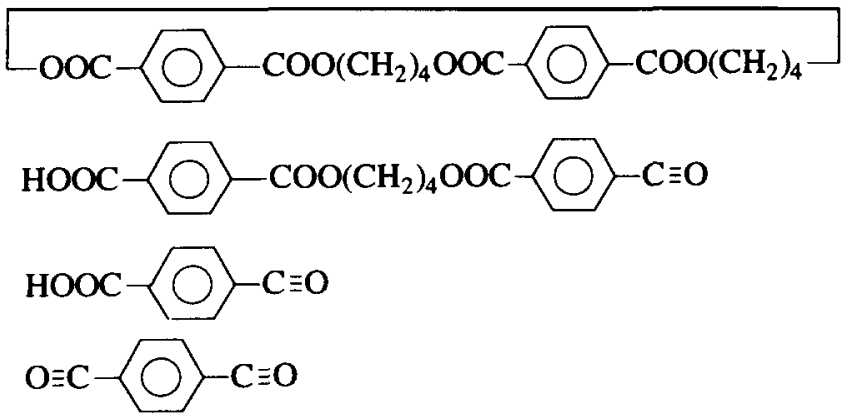

Table 6 Intensity of relevant ion currents (RIC) at 200 and $300^{\circ} \mathrm{C}$ for PBT and PBTA20

\begin{tabular}{|c|c|c|c|c|c|c|c|}
\hline Polymer & $\begin{array}{l}T \text { probe } \\
\left({ }^{\circ} \mathrm{C}\right)\end{array}$ & $\frac{438}{440}$ & $\frac{369}{440}$ & $\frac{367}{438}$ & $\frac{149}{440}$ & $\frac{132}{440}$ & $\frac{54}{440}$ \\
\hline \multirow[t]{2}{*}{ PBT } & 200 & 0 & 1.3 & 0 & 0.69 & 1.7 & 2.3 \\
\hline & 300 & 0 & 1.4 & 0 & 0.50 & 1.8 & 2.4 \\
\hline \multirow[t]{2}{*}{ PBTA20 } & 200 & 0.01 & 2.3 & 0.39 & 1.2 & 1.7 & 1.5 \\
\hline & 300 & 0.14 & 2.4 & 0.11 & 1.3 & 1.8 & 1.6 \\
\hline \multirow[t]{2}{*}{$\operatorname{PBTA20}^{\mathrm{a}}$} & 200 & 0.04 & 4.1 & 0.76 & 29 & 2.2 & 13 \\
\hline & 300 & 0.13 & 6.6 & 0.20 & 9.0 & 2.4 & 6.0 \\
\hline PBTA20 (calc.) & & 0.40 & & & & & \\
\hline
\end{tabular}

${ }^{a}$ Degraded $10 \mathrm{~h}$ at $270^{\circ} \mathrm{C}$ in vacuo before analysis

during the synthesis of T4T.dimethyl, which resulted in $250 \mathrm{ppm} \mathrm{Li}$ in PBTA20 . Table 4 shows that the thermal stability of PBTA2 $0^{\mathrm{a}}$ was similar to that of PBTA20 with only $6 \mathrm{ppm} \mathrm{Li}$ residue. So, $\mathrm{Li}$ has no significant influence on the thermal degradation of PBTA.

Ballistreri et al. ${ }^{31}$ found that sodium salts of simple carboxylic acids are capable of sensibly lowering the average decomposition temperature (ADT) of aliphatic-aromatic polyamides. In case of $\mathrm{Na}$ (benzoate), the ADT of nylon-4,T decreased from 470 to $420^{\circ} \mathrm{C}$ (Table 4), which allowed mass spectra of degradation products to be obtained at lower temperatures. Lüderwald ${ }^{39}$ reported that the base-catalysed degradation of nylon- 6 was strongly catalysed by $1-2 \mathrm{wt} \%$ of sodium and potassium carboxylates and much less by lithium carboxylates (by a factor of 10 lower). Therefore, the apparent inactivity of lithium residues in PBTA was ascribed to a stronger, maybe covalent, bonding of the cation to PBTA. The type of this salt and its dispersion in PBTA will determine its catalytic activity.

\section{Mass spectrometric measurements}

Degradation products and oligomers in PBT and PBTA20 up to $1000 \mathrm{~g} \mathrm{~mol}^{-1}$ could be detected by mass spectrometry (m.s.). The evaporation and/or pyrolysis took place close to an ionization chamber ('direct pyrolysis') in which the products were ionized by electron impact. A molecular ion or radical-cation $\left(\mathbf{M}^{\cdot+}\right)$ was fragmented into a cation, a radical and an anion [A, B and $\mathrm{C}$ in reaction (21)]. Only the positively charged ions were sorted on mass/charge $(\mathrm{m} / \mathrm{e})$ ratio and detected

$$
\mathrm{M}+\mathrm{e}^{-} \rightarrow \mathrm{M}^{++}+2 \mathrm{e}^{-} \rightarrow \mathrm{A}^{+}+\mathrm{B}^{+}+\mathrm{C}^{-}+\mathrm{e}^{-}
$$

Mass spectra (pyrograms). The mass spectra scanned at a certain temperature are, as 'fingerprints', 
more characteristic than the TIC curves mentioned above. The mass spectrum of PBTA20 at $300^{\circ} \mathrm{C}$ is presented in Figure 13. The mass spectrum of PBTA20 resembled that of $\mathrm{PBT}$ but both spectra contained far more degradation products than the mass spectrum of nylon- $4, T$ at $300^{\circ} \mathrm{C}$. At this temperature nylon $-4, T$ is still below its melting temperature(s) (peaks at 425 and $475^{\circ} \mathrm{C}$ ).

The thermal stability of PBTA20 was further compared with that of PBT by analysis of the exact degradation and fragmentation products and processes. In Table 5 the main thermal degradation products of PBT (reported by Burzin ${ }^{40}$ ) and nylon-4, T (reported by Ballistreri et al. ${ }^{31}$ ) are given. The main degradation products for PBT were cyclic ester-ester dimers $(m / e=440)$ and in less amount cyclic ester trimers $(m / e=660)$ formed by intramolecular cyclization. The thermal stability of the dimer can be measured by a determination of its fragmentation products. Lum ${ }^{10}$ reported that ester-ester dimers degrade via a ringopening by $\beta$-elimination according to McLafferty ${ }^{42}$. The radical cation with $m / e=440$ could split off a tetrahydrofuran radical $(m / e=71)$ by an $\alpha_{\mathrm{O}}$-break of the $\mathrm{C}-\mathrm{O}$ ester bond. It could also eliminate a butadiene molecule $(m / e=54)$, after abstraction of a hydroxyl radical. Both routes lead to the characteristic intensive peak at $m / e=369$. Lum $^{10}$ reported that the elimination of THF had a lower apparent activation energy than the elimination of butadiene (27.9 and $49.7 \mathrm{kcal} \mathrm{mol}^{-1}$, respectively). In a further degradation stage, terephthalic acid fragments were formed in $m / e=149,166$ and 203.

PBTA20 not only showed fragments from ester segment degradation, but also fragments containing amides, amines or the like. For example, at somewhat higher temperatures the ester-amide dimer with $m / e$ of 438 was detected. This dimer has a fragmentation pattern composed of PBT and aromatic-aliphatic polyamide degradation $^{31}$ processes. The ester bond probably degraded first and the amide bonds degraded either via $\beta$-elimination or hydrolysis. Although the polymers were dried thoroughly, water could always be formed by cyclization of butanediol or dehydration of amides.

The mass spectra of PBTA20 at temperatures from $50^{\circ} \mathrm{C}$ up to $360^{\circ} \mathrm{C}$ hardly contained fragments from amide degradation. Ester-amide dimers with $m / e=438$ and their fragments with $m / e=367$ were detected in lower amounts than expected from the esteramide ratio in the polymer (Table 6). This points to a high thermal stability of ester-amide sequences in PBTA. On the other hand, ester-amide interchange reactions in the melt may have enlarged the amount of stable amide blocks. Plage and Schulten ${ }^{42}$ reported the occurrence of amide exchange reactions in aliphatic nylon blends during pyrolysis in the mass spectrometer. Amide-amide dimers were not detected at all in PBTA20 and in the nylon-4,T mass spectra up to $360^{\circ} \mathrm{C}$.

The degradation of PBTA20 up to $360^{\circ} \mathrm{C}$ in the mass spectrometer appeared to be mainly caused by decay of the ester segment. However, the mass spectra could not differentiate real degradation products from degradation products by ionization. The volatile degradation compounds were fragmented further and could introduce ambiguities in the identification of the genuine products of pyrolysis.

\section{CONCLUSIONS}

Compared with PBT, the polymerization of PBTA had a lower maximum viscosity. The polymerization reaction in PBTA seemed to be retarded after $1 \mathrm{~h}$ due to the $\mathrm{OH} / \mathrm{COOH}$ imbalance in the system.

The thermal stability of PBT and PBTA20 has been followed during prolonged heating of the melt in a glass flask at $255-275^{\circ} \mathrm{C}$ and during heating experiments in the thermogravimeter (t.g.a.) and the mass spectrometer (m.s.).

From degradation tests in a stirred melt it appeared that the inherent viscosity of PBT and PBTA20 decreased with time. The concentration of carboxylic acid endgroups in PBT and PBTA20 increased linearly with time. An autocatalysing effect of the generated $\mathrm{COOH}$ endgroups was not observed. The viscosity and endgroup measurements indicated that $\beta$-elimination of ester linkages is the main thermal degradation mechanism. The degradation rate constant was approximately similar for PBT and PBTA20. In contrast with the result for alternating poly(ester amide) $6 \mathrm{NT}^{21}$, we found for PBTA20 no destabilizing effect of amide groups on neighbouring ester groups.

T.g.a. of PBT and PBTA20 demonstrated an equal thermal stability based on weight loss during heating at $10^{\circ} \mathrm{C} \min ^{-1}$. The lower and average decomposition temperatures of PBT and PBTA20 were located at about 395 and $420^{\circ} \mathrm{C}$, irrespective of nitrogen or air atmosphere. The presence of lithium residues in PBTA20 apparently had no effect on the rate of volatilization.

Mass spectra and ion currents of PBT and PBTA20 were determined at 200 and $300^{\circ} \mathrm{C}$. Ester-ester dimers, and for PBTA also ester-amide dimers, were detected as main degradation products. The rate of fragmentation, due to electron impact, of the ester-amide dimer was lower than that of the ester-ester dimer. This was another indication of the thermal stability of esteramide sequences in PBTA. Amide-amide sequences were not detected up to $360^{\circ} \mathrm{C}$.

Furthermore, it was measured by ${ }^{13} \mathrm{C}$ n.m.r. that ester-amide interchange reactions take place in the melt. The melting peaks of PBTA20 broadened and the maximum $\left(T_{\mathrm{m}, 2}\right)$ decreased linearly with increasing relative amide block fraction $\left(X_{\mathrm{AA}} / X_{\mathrm{A}}\right)$, as appeared in d.s.c. measurements. This effect was also observed for T4T.dimethyl. An explanation may be that a decreased uniformity of T4T units disturbs the crystallization of the unit itself and the crystallization of T4T in PBTA in the same manner. As a consequence, the purity of T4T determines its effectiveness in increasing the melting temperature of PBTA.

\section{ACKNOWLEDGEMENTS}

This research was financially supported by GE Plastics (Bergen op Zoom, The Netherlands). J. Bussink and J. Feijen are acknowledged for fruitful discussions and valuable suggestions. The t.g.a. measurements were kindly performed by Angelica Saez at GE Plastics, Bergen op Zoom.

\section{REFERENCES}

1 Carlson, D. G. and Wiles, D. M. in 'Encyclopedia of Polymer Science', 2nd Edn (Eds H. F. Mark, N. M. Bikales, 
C. G. Overberger, G. Menges and J. I. Kroschwitz), Wiley, New York, 1988, Vol. 4, p. 630

2 Hiemenz, P. C. 'Polymer Chemistry, The Basic Concepts', Marcel Dekker Inc., New York, 1984

3 Sykes, P. 'A Guidebook to Mechanism in Organic Chemistry', 6th Edn, Longman, Singapore, 1986

4 Binsack, R. in 'Kunststoff Handbuch 3/1' (Eds G. W. Becker and D. Braun), Hanser, Munich, 1992, Ch. 2

5 Ballistreri, A., Garozzo, D., Maravigna, P., Montaudo, G. and Giuffrida, M. J. Polym. Sci. Part A: Polym. Chem. 1987, 25, 1049

6 Van Bennekom, A. C. M. and Gaymans, R. J. Polymer 1996, 37, 5439

7 Pilati, F., Manaresi, P., Fortunato, B., Munari, A. and Passalacqua, V. Polymer 1981, 22, 1566

8 Jadhav, J Y and Kantor, $S$ W in 'Encyclopedia of Polymer Science', 2nd Edn (Eds H. F. Mark, N. M. Bikales, C. G. Overberger, G. Menges and J. I. Kroschwitz), Wiley, New York, 1988, Vol. 12, p. 217

9 Passalacqua, V., Pilati, F., Zamboni, V., Fortunato, B. and Manaresi, P. Polymer 1976, 17, 1044

10 Lum, R. M. J. Polym. Sci., Polym. Chem. Edn 1979, 17, 203

11 Deveaux, J., Godard, P. and Mercier, J.-P. Makromol. Chem. $1978,179,2201$

12 Hudson, B. G. and Barker, R. J. Org. Chem. 1967, 32, 3650

13 Zimmerman, H. and Hohmann, L. Acta Polym. 1980, 31, 686

14 Gaymans, R. J. J. Polym. Sci, Polym. Chem. Edn 1985, 23, 1599

15 Gaymans, R. J., Van Utteren, T. E. C., Van den Berg, J. W. A. and Schuyer, J. J. Polym. Sci., Polym. Chem. Edn 1977, 15, 537

16 Ballistreri, A., Garozzo, D., Giuffrida, M. and Montaudo, G. Macromolecules 1987, 20, 2991

17 Khanna, Y. P., Pearce, E. M., Forman, B. D. and Bini, D. A J. Polym. Sci., Polym. Chem. Edn 1981, 19, 2799

18 Khanna, Y. P., Pearce, E. M., Smith, J. S., Burkitt, D. T., Njuguna, H., Hindenlang, D. M. and Fozman, B. D. J. Polvm. Sci. Polym. Chem. Edn 1981, 19, 2817

19 Ballistreri, A., Garozzo, D., Maravigna, P., Montaudo, G. and Giuffrida, M. J. Polym. Sci. Part A: Polym. Chem. 1987, 25, 1049
20 Manzini, G., Crescenzi, V., Ciana, A., Della Fortuna, G. and Zotteri, L. Eur. Polym. J. 1973, 9, 941

21 Pilati, F., Masoni, S. and Fortunato, B. Polym. Commun. 1984, 25, 190

22 Kotliar, A. M. J. Polym. Sci.: Macromol. Rev. 1981, 16, 367

23 Korshak, V. V. and Frunze, T. M. 'Synthetic Hetero-Chain Polyamides', S. Monson, Jerusalem, 1964 (translated by N. Kaner)

24 Flory, P. J. J. Am. Chem. Soc. 1942, 64, 2205

25 Korshak, V. V., Vinogradova, S. V., Teplyakov, M. M. and Chernomordik, Yu.A. Doklady Akademii Nauk SSSR 1962, 147,1365

26 Della Fortuna, G., Oberrauch, E., Salvatori, T., Sorta, E. and Bruzzone, M. Polymer 1977, 18, 269

27 Dimov, K. and Georgiev, J. Faserforschung und Textiltechnik $1973,24,120$

28 Inoshita, K., Terekawa, M. and Yasuda, T. Japan Patent 7228916, 1972

29 Pillon, L. Z. and Utracki, L. A. Polym. Proc. Eng. 1986, 4(2-4), 375

30 Brown, S. B. in 'Reactive Extrusion' (Ed. M. Xanthos), Hanser, Munich, 1992, Ch. 4

31 Ballistreri, A., Giuffrida, M., Maravigna, P. and Montaudo, G. J. Polym. Sci., Polym. Chem. Edn 1985, 23, 1145

Tuckett, R. F. Trans. Faraday Soc. 1945, 41, 351 Casassa, E. F. J. Polym. Sci. 1949, 4, 405

Raju, K. V. S. N. and Yaseen, M. J. Appl. Polym. Sci. 1992, 45, 677 Pitt, C. G. and Gu, Z. J. Contr. Rel. 1987, 4, 283

Rafler, G., Blaesche, J., Möller, B. and Stromeyer, M. Acta Polym. 1981, 32, 608

37 Yamadera, R. and Murano, M. J. Polym. Sci., Part Al 1967, 5. 2259

38 Van Bennekom, A. C. M. and Gaymans, R. J. Polymer in press

39 Lüderwald, L. Makromol. Chem. Rapid Commun. 1982, 25, 1049

40 Burzin, K. and Frenzel, P. J. Angew, Makromol. Chemie 1978, 71, 61

41 McLafferty, F. W. Chem. Commun. 1966, 78, 78

42 Plage, B. and Schulten, H.-R. J. Appl. Polym. Sci. 1989, 38, 123 